\title{
CONTRIBUIÇÕES DA EDUCAÇÃO AMBIENTAL PARA A GESTÂO INTEGRADA EM MOSAICOS DE ÁREAS PROTEGIDAS: O CASO DO MOSAICO CENTRAL FLUMINENSE (RJ)
}

\author{
Frances Vivian Correa ${ }^{1}$ \\ Marina Ferreira Praça ${ }^{2}$ \\ Carlos Frederico B. Loureiro ${ }^{3}$ \\ Nahyda Franca ${ }^{4}$
}

Resumo: A partir da perspectiva crítica da Educação Ambiental, objetiva-se discutir o processo de fortalecimento da gestão integrada de mosaicos de áreas protegidas. $\mathrm{O}$ artigo inicia com uma discussão sobre gestão de UCs no Brasil e sobre os pressupostos metodológicos da Educação Ambiental que fundamentam as estratégias de gestão participativa nesses espaços territoriais. Com esse aporte conceitual, é descrito o caso do Mosaico Central Fluminense. $\mathrm{Na}$ sequência são feitas considerações que permitem pensar as práticas de Educação Ambiental em mosaicos, reforçando sua validade e ao mesmo tempo indicando as dificuldades inerentes a um espaço mediado pelas contradições existentes em uma sociedade socialmente desigual e ambientalmente injusta.

Palavras-chave: Mosaicos de Áreas Protegidas; Educação Ambiental; Gestão Integrada e Participativa.

2 Universidade Federal do Rio de Janeiro, Rio de Janeiro, RJ: E-mail: mpraca88@hotmail.com 3 Universidade Federal do Rio de Janeiro, Rio de Janeiro, RJ: E-mail: fredericoloureiro89@gmail.com 4 Instituto Brasileiro de Análises Sociais e Econômicas, Rio de Janeiro, RJ: E-mail: nahyda@ibase.br Revbea, São Paulo, V.11, № 2: 342-356, 2016. 


\section{Introdução}

O estado do Rio de Janeiro tem a maior concentração de áreas protegidas do bioma Mata Atlântica e ecossistemas associados do Brasil. Contudo, apesar de ser uma indiscutível conquista para a conservação, grande parte de tais áreas, que correspondem a aproximadamente $13 \%$ de sua cobertura original, encontra-se sob forte pressão por parte de diferentes agentes sociais. Esse fato é decorrente do desenvolvimento econômico em curso no país, intensivo na demanda por recursos naturais, e que impõe um profundo rearranjo do padrão de ocupação e uso do solo.

Nesse contexto econômico de reordenamento territorial (social e ambientalmente desigual) se manifestam as dificuldades operacionais das políticas de conservação. No caso do Rio de Janeiro, de um modo geral, as unidades de conservação (UCs) estaduais e principalmente as municipais não foram, no momento de sua criação, devidamente estruturadas para garantir a proteção da biodiversidade no cumprimento de suas atribuições legais (fiscalização, recuperação, estudos científicos, educação e comunicação ambiental, atividades econômicas e culturais sustentáveis etc.). Mesmo as UCs federais, que contam, comparativamente, com equipes maiores e em condições materiais mais ajustadas às necessidades territoriais e de gestão, estão distantes de patamares ideais, apresentando dificuldades para garantir o cumprimento de suas competências institucionais e para fomentar maior articulação com UCs de outras esferas administrativas.

Além desses aspectos, é fato que no âmbito da conservação, até por força do histórico de constituição do campo no Brasil, é modesto o interesse em se consolidar uma gestão participativa e integrada a políticas públicas que assegurem uma sustentabilidade territorial capaz de contemplar conservação da biodiversidade e manutenção dos modos de vida dos grupos sociais vulnerabilizados em seus direitos e na possibilidade de se reproduzirem socialmente e, principalmente, dos povos tradicionais. Classicamente, a diversidade social não é vista em sua íntima relação de constituição e dependência com a diversidade biológica e não raramente sociedade e natureza são apresentados como polos dissociados.

No estado do Rio de Janeiro, entre 2007 e 2014, como movimento de reconhecimento/enfrentamento desse cenário por parte de setores "socioambientalistas" ocupantes de espaços na estrutura estatal de meio ambiente em dois mandatos governamentais, se observou esforços de superação em iniciativas oriundas da Secretaria de Estado do Ambiente do Rio de Janeiro - SEA/RJ e seus órgãos vinculados (à época, IEF e FEEMA, e desde janeiro de 2009, o INEA - Instituto Estadual do Ambiente, que sucedeu os dois anteriores). Tais iniciativas tiveram como foco não apenas 0 fortalecimento dos conselhos das UCs e melhoria de infraestrutura, mas também a criação e estruturação de mosaicos de áreas protegidas e corredores ecológicos, como condição para se pensar a potencialização das iniciativas estritamente de competência da conservação, bem como daquelas decorrentes da articulação com outras políticas públicas.

revista brasileira educação ambiental 
A proteção da sociobiodiversidade ainda não está garantida. Isso é um fato, cujas determinações macroeconômicas e político-institucionais se vinculam às deficiências no cumprimento do que cabe à conservação (FLEURY; ALMEIDA, 2007; MOUTINHO DA COSTA, 2011). Nesse sentido, sob a perspectiva da justiça ambiental (ACSELRAD, 2004, 2009) e da perspectiva crítica de Educação Ambiental adotada no âmbito da gestão ambiental pública (QUINTAS, 2000), os mosaicos são importantes aliados para se fazer a gestão das áreas protegidas enquanto componentes integrantes e integrados a um determinado território, potencialmente superador de modelos de gestão que reproduzem a cisão sociedade-natureza.

A pesquisa que referencia o trabalho teve como ponto de partida 0 projeto "Mosaicos da Mata Atlântica: fortalecimento da sociobiodiversidade e apoio à gestão integrada de Mosaicos de Áreas Protegidas" coordenado pela Superintendência de Educação Ambiental da Secretaria de Estado do Ambiente do Rio de Janeiro (SEAM - SEA/RJ). Este foi executado entre junho de 2013 e setembro de 2014 pelo Instituto Brasileiro de Análises Sociais e Econômicas (lbase) e teve ênfase no fortalecimento da gestão integrada dos Mosaicos de Mata Atlântica do Rio de Janeiro, utilizando-se das diretrizes da Educação Ambiental crítica incorporadas na proposta de educação no processo de gestão ambiental instituída pelo IBAMA e pelo ICMBio (LOUREIRO; SAYSSE, 2014). Tais diretrizes e respectivas orientações normativas no aparato estatal preconizam que no espaço público de gestão do ambiente o processo educativo deve se voltar para a participação igualitária de agentes sociais envolvidos na definição dos rumos das políticas ambientais e na gestão destas, assegurando ações variadas de informação, divulgação, mobilização, organização e formação.

Nesse contexto e diante da perspectiva teórica assumida (a Educação Ambiental crítica), o objetivo deste artigo é discutir a Educação Ambiental no processo de fortalecimento da gestão integrada de mosaicos de áreas protegidas, tendo como foco a participação e o controle social. Para tanto, metodologicamente realizou-se um estudo de caso (YIN, 2015) a partir dos processos participativos advindos da dinâmica de funcionamento do Mosaico Central Fluminense (MCF), localizado no Estado do Rio de Janeiro. A escolha desse mosaico, entre os cinco existentes no estado, teve por critério básico o reconhecimento público existente por parte dos participantes da gestão de mosaicos de que o MCF é o que possui o histórico mais consolidado de gestão participativa no âmbito de suas ações e no funcionamento do seu conselho.

Para cumprir tal objetivo, o artigo inicia com uma discussão ampla sobre gestão de UCs no Brasil e sobre os pressupostos metodológicos da Educação Ambiental que fundamentam as estratégias de criação e fomento da gestão participativa nesses espaços territoriais. Com base nesse aporte histórico, normativo e conceitual, é descrito de modo analítico o caso estudado (o MCF). $\mathrm{Na}$ sequência se apresenta algumas considerações que sintetizam o processo pesquisado e que permitem pensar as práticas de Educação Ambiental em unidades de gestão como os mosaicos, reconhecendo-se as mediações 
determinadas por uma sociedade socialmente desigual e ambientalmente injusta.

\section{Políticas Públicas de Gestão Integrada de UCs: subsídios à discussão}

Além das UCs, foram reconhecidos pelo Sistema Nacional de Unidades de Conservação - SNUC - lei no. 9.985/2000 outros instrumentos de gestão e ordenamento territorial que têm por fim a conservação da biodiversidade. São eles: as reservas da biosfera, os corredores ecológicos e os mosaicos. Esses representam o referencial básico para a integração entre as unidades de conservação e demais áreas protegidas de um determinado território ou região, podendo atuar de forma complementar e sobreposta.

A regulamentação do SNUC, por meio do decreto o․ 4.340/2002, traz um capítulo centrado na gestão dos mosaicos. Neste se afirma que:

(...) quando existir um conjunto de unidades de conservação de categorias diferentes ou não, próximas, justapostas ou sobrepostas, e outras áreas protegidas públicas ou privadas, constituindo um mosaico, a gestão do conjunto deverá ser feita de forma integrada e participativa, considerando-se os seus distintos objetivos de conservação, de forma a compatibilizar a presença da biodiversidade, a valorização da sociodiversidade e o desenvolvimento sustentável no contexto regional (Art.26).

Ainda de acordo com este decreto, um conjunto de unidades de conservação só passa a ser tratado como mosaico após seu reconhecimento por ato do Ministério do Meio Ambiente, a pedido dos órgãos gestores das unidades que o compõe. Uma vez aceito como mosaico, esse conjunto deve dispor de um conselho de caráter consultivo e com função de atuar como instância de gestão integrada, compatibilizando e otimizando as atividades de pesquisa, fiscalização e manejo das unidades do mosaico.

Enquanto as UCs são unidades territoriais com foco na proteção dos remanescentes do bioma, os mosaicos possuem foco na gestão do território. Foram criados enquanto mecanismo de gestão integrada de UCs e outras áreas protegidas como terras ocupadas por remanescentes das comunidades de quilombos, terras indígenas e áreas de proteção permanente.

Por outro lado, a estratégia específica para organização e ligação de várias unidades de conservação, fragmentos de biomas e áreas protegidas é feita por meio dos corredores ecológicos. Estes conectam áreas geográficas relevantes para a conservação, possibilitando entre elas o fluxo genético de fauna e flora, facilitando a dispersão de espécies e a recolonização de áreas degradadas. 
Os mosaicos são complementares aos corredores ecológicos (PINHEIRO, 2010), uma vez que se constituem em instância políticoadministrativa articuladora da gestão das UCs e áreas protegidas, e em instância promotora de ações que resultem em políticas públicas favoráveis à conservação. As finalidades dos mosaicos, portanto, se relacionam à fiscalização e proteção de paisagens, à garantia de serviços ambientais e à promoção de arranjos produtivos e culturais de grupos tradicionais e originários.

Junto a esta função de gestão territorial se coloca a necessidade de fortalecimento da capacidade de gestão dos conselhos consultivos dos mosaicos para que eles operem na perspectiva da participação e controle social. Para isso, é estratégica a construção coletiva de mecanismos de sustentabilidade com base conceitual e legal, bem como a criação de canais de diálogo com os grupos sociais que possuem o direito, garantido pelo SNUC, de atuar em tais espaços públicos. É exatamente nesse ponto, da gestão pública do território associada às exigências da participação e controle social, que a Educação Ambiental crítica foi historicamente apropriada pelos órgãos ambientais federais e configurada enquanto proposta orientadora das ações no âmbito da gestão ambiental pública. O eixo estrutural da prática educativa em espaços de gestão pública, ao estar na participação nos espaços instituídos, permite a articulação de ações e projetos com comunidades do entorno, escolas, grupos sociais envolvidos com a UC, entre outros, em processos que garantem a atuação não só a curto prazo, mas planejada e organizada para intervenções de longo prazo. E ao se colocar a Educação Ambiental como elemento estruturante, evitam-se os problemas recorrentes de ações fragmentadas, isoladas e de curta duração, que se verificam em relatos de gestores de UCs em todo o país.

Cabe ressaltar que, independente do avanço existente em incorporar a participação social na implementação das políticas ambientais e, em especial, na gestão de unidades de conservação, tanto a Lei n ${ }^{\circ}$ 9985/2000, que institui o SNUC, quanto 0 seu decreto de regulamentação, tratam apenas superficialmente de normas e diretrizes relacionadas à democratização dos procedimentos de criação das UCs e de seus instrumentos de gestão. Isto faz com que os gestores de unidades de conservação e, mais recentemente, dos mosaicos tenham diferenciados entendimentos e práticas no que diz respeito à implantação e ao funcionamento dos conselhos. Nesse contexto, há uma tensão entre o papel que cumprem os conselhos e a sua finalidade, que é imprimir um novo formato às políticas públicas e ao processo de tomada de decisões.

No entanto, se há ausências significativas no SNUC e demais normas da conservação, a Constituição de 1988 trouxe a institucionalização de espaços públicos que possibilitam a inserção da população nas decisões políticas (conselhos, comitês, audiências públicas, referendos populares, plebiscitos, conferências setoriais, etc.). Foi a partir daí que o conceito de controle social passou a ser usado e enfatizado pela sociedade para designar a possibilidade 
da participação da sociedade civil nos espaços de deliberação e construção de políticas públicas. A perspectiva constitucional adotada é a de se criar espaços democráticos de atuação social nas definições e decisões relativas às políticas públicas, universalizando direitos e conquistas sociais, dentre elas as que garantem a proteção, a conservação, a preservação e a recuperação ambiental.

Em última instância, o significado mais amplo da ideia de controle social mantém um elo entre a democracia representativa e a participativa. Sob esta perspectiva o cidadão, além de votar em um representante, pode acompanhar ativamente as ações vinculadas às políticas públicas, e reivindicar espaços que possibilitem o debate entre o Estado e os diferentes setores sociais.

Desse modo, as ausências normativas sobre participação e controle social em UCs não justificam posturas que minimizem ou ignorem a importância do tema, previsto constitucionalmente. Cabe aos órgãos ambientais a disposição e o interesse em trocar experiências e dialogar com aqueles que vivenciam processos participativos, seja na própria gestão de UCs ou em outros espaços públicos.

Outro instrumento de gestão territorial contemplado pelo SNUC é a Reserva da Biosfera da Mata Atlântica - RBMA, que foi a primeira unidade da Rede Mundial de Reservas da Biosfera declarada no Brasil. A articulação com esta instância é vista como estratégica e fundamental para se pensar a operacionalização dos mosaicos e a materialização de políticas públicas de interesse destes.

A RBMA é a maior reserva da biosfera em área florestada do planeta, com cerca de 35 milhões de hectares, abrangendo áreas de 15 dos 17 estados brasileiros onde ocorre a Mata Atlântica, o que permite ações de conservação na escala de todo o bioma. Essa reserva atravessa a área mais densamente populosa e urbanizada do país. No seu entorno, encontram-se cerca de 120 milhões de habitantes e atividades econômicas que respondem por aproximadamente $70 \%$ do PIB brasileiro, além de abranger as duas maiores metrópoles do país - São Paulo e Rio de Janeiro.

Dentre as suas funções estão: a) conservação da biodiversidade e dos demais atributos naturais da Mata Atlântica incluindo a paisagem e os recursos hídricos; b) a valorização da sociodiversidade e do patrimônio étnico e cultural a ela vinculados; c) o fomento ao desenvolvimento econômico que seja social, cultural e ecologicamente sustentável; d) o apoio a projetos demonstrativos, à produção e difusão do conhecimento, à Educação Ambiental e capacitação, à pesquisa científica e ao monitoramento nos campos da conservação e do desenvolvimento sustentável ${ }^{5}$.

Como é um tema complexo e com especificidades, além do recorte escolhido para a elaboração do texto ser mosaicos, no presente artigo não será

\footnotetext{
${ }^{5}$ www.rbma.org.br/index.asp
}

revista brasileira educação ambiental 
tratada a RBMA e como esta tem operado no que se refere aos processos de Educação Ambiental, garantindo o foco nos mosaicos, sem, contudo, deixar de comentar a existência de outros modelos de gestão territorial dispostos nas normas legais.

\section{Proposta metodológica de gestão participativa em UCs: a Educação Ambiental crítica como base}

Para consolidar a Política Nacional de Educação Ambiental (PNEA), e demais instrumentos da política ambiental, fortalecendo processos sociais de reversão das condições assimétricas econômicas e de poder que estão na base da degradação ambiental, a prática educativa na gestão ambiental pública se destaca por promover a participação permanente do cidadão coletivamente organizado na definição dos usos e nas decisões que afetam a qualidade ambiental. Isso significa exercer o direito democrático de intervir na elaboração e execução de políticas públicas que afetam a vida e o ambiente. Logo, a gestão pública é o lugar onde o conhecimento, as habilidades, as atitudes e os valores são construídos pela educação com a intenção clara de intervir na realidade para transformá-la em favor dos interesses coletivos e comuns a todo o cidadão (LOUREIRO, 2014).

A Educação Ambiental crítica no processo de gestão pública do ambiente tem como especificidade a operacionalização e prática voltadas para a materialização da práxis educativa no campo da gestão ambiental (licenciamento, portos, unidades de conservação, águas, pesca etc.). Significa, portanto, fundamentalmente estabelecer processos sociais, políticoinstitucionais e práticas educativas que fortaleçam a participação dos sujeitos e grupos em espaços públicos, o controle social das políticas públicas e a reversão das assimetrias no uso e apropriação de recursos naturais, tendo por referência os marcos regulatórios da política ambiental brasileira. São nesses processos instituídos junto aos instrumentos da política ambiental que as práticas educativas podem promover a participação do cidadão coletivamente organizado na gestão dos usos e nas decisões que afetam a qualidade ambiental e o padrão de desenvolvimento do país. Isso significa favorecer o direito democrático de atuação na elaboração e execução de políticas públicas que interferem no ambiente e no acompanhamento de empreendimentos que alteram propriedades do território em que se vive.

Desse modo, no âmbito das políticas de conservação, a opção por uma Educação Ambiental que privilegie o processo constitutivo e de fortalecimento dos conselhos, enquanto momento educativo e de exercício da cidadania, dáse por entendê-la como fundamental para o funcionamento desse espaço público onde estão inscritas as intencionalidades, diálogos e disputas dos agentes sociais que participam do processo gestionário das unidades de conservação (LOUREIRO; SAISSE; CUNHA, 2013) e, no âmbito desta pesquisa, dos mosaicos de Mata Atlântica. 
A inserção da obrigatoriedade de constituição dos conselhos de UCs no SNUC possibilita importantes avanços no campo da gestão participativa, processo com o qual se pretende, primordialmente: legitimação de espaços públicos democráticos no âmbito das políticas de conservação e proteção; compartilhamento de responsabilidades na proteção da UC; estabelecimento de relações entre a UC e seu entorno, buscando integrar questões, ampliar a compreensão da realidade e resolver problemas de forma mais efetiva; valorização da cultura local e modos alternativos e sustentáveis de organização e produção; garantia do diálogo e o acesso a informações estratégicas aos agentes sociais envolvidos com a gestão assim como com aqueles que são afetados pela criação da UC.

Considera-se que ampliar e fortalecer $o$ debate público sobre participação, uso público, gestão integrada e controle social de UCs, visando à criação de bases teórico-metodológicas consistentes que possam servir como referências para experiências similares no país é um desafio que deve ser enfrentado diante da baixa efetividade dos instrumentos de gestão territorial que abarcam a conservação, do ponto de vista da participação popular e da justiça ambiental. Isso decorre do distanciamento histórico em que esta área se colocou frente a outras políticas públicas com fortes impactos no ordenamento territorial, e também pela desconsideração para com a conservação presente nessas outras políticas, reproduzindo uma lógica de intervenção social que dissocia sociedade e natureza.

Nesse contexto, emerge a necessidade de fortalecer os mosaicos como estratégia de gestão do território na perspectiva da conservação da sociobiodiversidade da Mata Atlântica e estabelecer e acordar, com os grupos estratégicos do território, formas de viabilizar a gestão integrada e participativa dos mosaicos.

Em termos metodológicos, no que se refere ao escopo da pesquisa e da intervenção ocorrida nos mosaicos do estado do Rio de Janeiro, para a realização do processo educativo ambiental na gestão destes, foram utilizadas as premissas das metodologias participativas (BROSE, 2001), que são as mais propícias para o fomento de conselhos como instrumentos democráticos de gestão. Tais metodologias, no geral, partem da não neutralidade do conhecimento, situando-o em um universo de intencionalidades e projetos societários em disputa. Para tanto, concebem como necessário o diálogo transparente entre agentes sociais que devem estar em condições minimamente igualitárias para atuar e decidir, buscando acordos e consensos, sem desconsiderar o caráter estrutural dos conflitos socioambientais. Pelo contrário, considerando-os como centrais no processo instituído e no reconhecimento de cada sujeito em sua materialidade social.

Diante desse referencial teórico-metodológico é que se analisou as contribuições da Educação Ambiental nas ações de reestruturação e fortalecimento do conselho consultivo do Mosaico Central Fluminense, tendo como premissas básicas as diretrizes sucintamente comentadas da Educação 
Ambiental crítica e as exigências legais e cidadãs de participação e controle social nos espaços de conservação.

\section{Mosaico Central Fluminense: conselho gestor e a construção de governança territorial}

O Mosaico Central Fluminense (MCF) foi reconhecido por meio da Portaria N. 350, de 11 de Dezembro de 2006 envolvendo 33 unidades de conservação. Segundo membro representante do colegiado ampliado do conselho gestor, atualmente o MCF é composto por cerca de 40 unidades de conservação (UCs) ${ }^{6}$ localizadas em 18 municípios no Estado do Rio de Janeiro e abrangendo uma área de $259.818,97$ ha (MELO, 2012). A maioria das UCs que o compõem é da esfera municipal (cerca de metade delas), as restantes se dividem entre Reservas Particulares de Patrimônio Natural (RPPNs) e unidades das esferas estaduais e federais. O número de UCs pertencentes ao mosaico é volátil devido à frequente inclusão de novas unidades de conservação com inserção e atuação no território do Mosaico.

Foi criado em 2003 a partir da mobilização de gestores de algumas destas unidades de conservação, que contaram com o apoio do Núcleo de Mosaicos da Superintendência Estadual do IBAMA, à época, responsável pela gestão de UCs, até a criação do ICMBio em 2009. Este processo teve continuidade em 2005 com o Conselho Nacional da Reserva da Biosfera da Mata Atlântica (RBMA) através do "Projeto de Apoio ao Reconhecimento dos Mosaicos na Serra do Mar". Com este buscou-se a criação de uma identidade territorial, em um processo em que os próprios gestores definiram a delimitação do território do MCF. Com isso, percebe-se ainda hoje que alguns gestores, principalmente das UCs da esfera federal, são mais engajados e compromissados com a gestão do Mosaico do que outros.

A criação do MCF foi motivada pelo fato deste mosaico abranger importantes e significativas porções do Bioma Mata Atlântica e representar uma alternativa no sentido de otimizar a gestão das unidades de conservação na região Central Fluminense do Estado do Rio de Janeiro. O mosaico foi criado também para a promoção de ações de combate à fragmentação da Mata Atlântica, principalmente nas regiões da Serra dos Órgãos, do Maciço do

\footnotetext{
${ }^{6}$ Área de Proteção Ambiental Guapimirim ,Área de Proteção Ambiental Petrópolis, Estação Ecológica Guanabara, Parque Nacional da Serra dos Órgãos, Reserva Biológica Tinguá ,APA da Bacia do Rio dos Frades, APA da Floresta do Jacarandá , APA da Bacia do Rio Macacu, APA de Macaé de Cima, Estação Ecológica do Paraíso, Parque Estadual Três Picos, Reserva Biológica de Araras, Área de Proteção Ambiental Maravilha, Parque Natural Municipal da Araponga, Monumento Natural Pedra das Flores, Estação Ecológica Monte das Flores, Área de Proteção Ambiental Guapi-Guapiaçu, Parque Natural Municipal da Taquara, RPPN CEC Tinguá, RPPN El Nagual, RPPN Querência, RPPN Graziela Maciel Barroso, Parque Natural Municipal Montanhas de Teresópolis, RPPPN Fazenda Suspiro, Parque Natural Municipal de Petrópolis, APA Jaceruba, APA Suruí, Parque Natural Municipal Serra do Barbosão, Monumento Natural da Pedra do Colégio, RPPN Sítio Serra Negra, APA Vale do Piabanha, APA Vale Fagundes, APA Lagoa do Morro Grande.
} 
Tinguá e Macaé de Cima, e da parte leste da Baía da Guanabara, áreas estratégicas no âmbito do Pacto para a Restauração da Mata Atlântica do Estado do Rio de Janeiro. Situado na região central do Estado, próximo à região metropolitana da cidade do Rio de Janeiro, o MCF está sob a influência de diversos projetos e empreendimentos de desenvolvimento econômico em seu território.

De acordo com Melo (2012), para entender a dinâmica territorial é necessário pensar não somente as atividades socioeconômicas presentes no território deste mosaico como a agropecuária, o turismo rural, o desenvolvimento das zonas urbanas e dos polos industriais, apenas para citar alguns, mas é fundamental considerar os projetos de desenvolvimento que vem sendo implementados no âmbito do estado do Rio de Janeiro. Dentre eles, dois podem ser considerados de maior influência no território, o Complexo Petroquímico do Rio de Janeiro (Comperj), da Petrobras, e a construção do Arco Metropolitano do Rio de Janeiro (AMRJ), que permitirá o escoamento da produção do Comperj até o Porto de Itaguaí.

Portanto, a gestão deste mosaico se materializa em um contexto territorial de confronto direto entre as estratégias de desenvolvimento e de conservação da biodiversidade, evidenciado pela expansão da atividade empresarial de grande escala sobre a base de recursos naturais. Assim, para além do desafio de integração das unidades de conservação que compõem o MCF, existe também o desafio estratégico de integração das políticas públicas de conservação da biodiversidade e de desenvolvimento, em um mesmo território (MELO, 2012).

Nesse contexto, para dar início ao processo de fortalecimento do conselho consultivo do MCF, foi realizada uma imersão e análise das ações previstas no Plano Estratégico. As atividades desenvolvidas foram elaboradas de forma participativa, e consistiram em oficinas, reuniões, debates e seminários, sempre com ampla participação dos conselheiros do MCF.

Os três planos de gestão integrada previstos inicialmente no escopo do projeto (Fiscalização, Proteção a Biodiversidade e Fomento ao turismo), foram adaptados para atender as reais demandas do território e passaram a ter a seguinte denominação: Plano de Proteção e Fiscalização, Plano de Recuperação e Conectividade Florestal e Plano de Comunicação / Fomento ao Turismo.

No que diz respeito ao processo de elaboração do Plano de Comunicação e Fomento ao Turismo, foi promovido em agosto de 2013 o Encontro Mosaico Central Fluminense: gestão, comunicação e sustentabilidade. Neste evento, além da discussão acerca do conceito de educomunicação, foram discutidas as estratégias de comunicação que já vinham sendo adotadas no território. Este também possibilitou o debate sobre turismo de base comunitária, e sobre arranjo produtivo local, por meio de apresentação de casos reais locais. Neste momento, foram visualizadas as possibilidades de confluências dos temas do turismo e da comunicação e 
iniciou-se o delineamento de um plano de gestão integrada que englobasse ambos.

No entanto, é importante salientar que no âmbito do Conselho do MCF, o tema de fomento ao turismo ainda se coloca frágil nas discussões. Essa temática vem ganhando força aos poucos e começa a despontar como algo a ser amadurecido pelo grupo que integra a Câmara Técnica de Educação Ambiental e Divulgação e que está à frente da organização dos Encontros de Comunidade do território. Como desdobramento deste evento foi constituído o Grupo de Trabalho Comunidades com o objetivo de organizar o V Encontro de Comunidades e sensibilizar e mobilizar as populações no território do Mosaico Central Fluminense. A intenção neste momento foi fortalecer as comunidades do entorno para o controle social e articular suas potencialidades no que diz respeito a arranjos produtivos locais. A partir desta discussão, a questão do turismo, com uma perspectiva comunitária, aliada a temas como agricultura familiar, agricultura orgânica, agroecologia, hortas medicinais, artesanato, dentre outros, vem surgindo como uma das formas de fortalecimento das cadeias produtivas locais.

$\mathrm{Na}$ discussão sobre o processo de elaboração do Plano de Gestão Integrada de Proteção e Fiscalização no MCF a prioridade dada pelos conselheiros foi no acompanhamento das condicionantes ambientais do COMPERJ que incidem na integridade das UCs do território do MCF. Esta questão apontou, à época, para uma sinergia entre os Planos de Gestão Integrada de Proteção e Fiscalização e de Recuperação e Conectividade Florestal a partir de ações em curso derivadas do acompanhamento das condicionantes ambientais do COMPERJ7.

Neste sentido, a primeira ação apontada para a elaboração dos Planos de gestão integrada referente aos dois temas foi a organização de um Seminário com participação da Petrobras, INEA e MCF com foco em recursos hídricos e restauração florestal. Desta forma, o Seminário Acompanhamento das condicionantes do COMPERJ relacionadas à integridade das UCs para construção dos Planos de Proteção da Biodiversidade e Restauração Florestal do Mosaico de Áreas Protegidas Central Fluminense aconteceu em novembro de 2013 reunindo cerca de 120 pessoas no auditório do INEA. Este evento fortaleceu não só o MCF em suas atribuições, mas também ajudou a criar canais de diálogo entre o mosaico, o poder público e a empresa licenciada no cumprimento das condicionantes de licença ambiental.

Como desdobramento deste seminário, um Grupo de Trabalho foi constituído com objetivo de promover a troca de informação ágil no acompanhamento das condicionantes priorizadas. O Grupo teve como produto

\footnotetext{
${ }^{7}$ O Complexo Petroquímico do Rio de Janeiro (COMPERJ) é um complexo industrial que está sendo construído pela Petrobrás no município de Itaboraí (RJ) onde serão produzidos derivados de petróleo e produtos petroquímicos. Atualmente é o empreendimento de maior influência no território do mosaico e foi priorizado pelos conselheiros devido às proporções de alto investimento e de impactos por ele gerados na região.
}

Revbea, São Paulo, V.11, № 2: 342-356, 2016. 
uma carta de recomendação para aperfeiçoar o processo de restauração na área do COMPERJ8.

Cabe ressaltar a importância dessa conquista para os que buscam uma gestão ambiental pública, pois é histórica, no licenciamento, a falta de transparência na disponibilização de informações tanto por parte da empresa como também do órgão licenciador. Estabelecer, portanto, processos de transparência, participação, análise conjunta das orientações técnicas mais adequadas para a realidade impactada e acompanhamento do que vem sendo executado, é uma demonstração de aprofundamento da democracia e respeito à população.

\section{Aprendizados e desafios da Educação Ambiental na gestão integrada de territórios}

A análise do processo pelo qual passou o MCF gera muitas reflexões e debates sobre o papel da Educação Ambiental para a construção de uma gestão integrada do território.

A consolidação da experiência vivida no MCF traz ao debate contribuições efetivas para a atuação de gestores públicos e representantes da sociedade civil envolvidos em mosaicos de áreas protegidas nos diferentes biomas existentes no país e, como consequência, para as tomadas de decisão no âmbito dos seus respectivos conselhos. Entende-se que a análise de uma realidade específica - fortalecimento da gestão integrada de um determinado mosaico no estado do Rio de Janeiro - pode ser levada para o cenário nacional, uma vez que esta constitui-se em meio aos aspectos estruturais que engendram os meandros contraditórios da política ambiental, a qual se realiza de modo subordinado às relações econômicas que, de forma dominante, reduzem a natureza a recursos transformados em mercadorias e a gestão pública a um espaço técnico ou a uma gestão empresarial.

A prática da gestão integrada e participativa a partir de um mosaico de áreas protegidas revela necessariamente a complexidade deste processo, cheio de avanços e recuos ao longo do tempo. Esse aspecto é fundamental. Não raramente parte-se de um ilusório entendimento de que a ação conjunta implica em constantes avanços. A participação e a estruturação de espaços democráticos são mediados por interesses conflituosos e contextos macroeconômicos e políticos que resultam em movimentos permanentes de avanços e recuos. Nem por isso a gestão integrada e participativa perde seu valor como princípio organizador e é diante disso que a validade da Educação Ambiental crítica na gestão pública do ambiente se afirma. Destaca-se também que no processo social não há um padrão específico a ser seguido, mas a

\footnotetext{
${ }^{8} \mathrm{O}$ documento Contribuições do MCF para a melhoria do processo de restauração na área do COMPERJ se encontra disponível nos sites: www.ibase.bre www.mosaicocentral.org.br
} 
riqueza está em saber compreender a realidade contraditória em que se age, intervir com serenidade, e principalmente, estabelecer espaços efetivamente igualitários e participativos de diálogo e de tomada de decisão.

Neste cenário, a questão central que se coloca, quando se pensa nesse processo educativo na gestão ambiental, é como fazer com que nas relações cotidianas e na atuação de cada ator estratégico que compõe um conselho gestor, os interesses coletivos sejam dispostos acima dos interesses pessoais e institucionais, assegurando o ambiente como um direito e um bem comum. Mais do que isso, a questão a ser pensada e enfrentada é até que ponto interesses particularistas podem ser efetivamente confrontados e tensionados diante da necessidade de se cumprir com as finalidades de conservação com justiça ambiental e participação social, sabendo-se dos limites que uma institucionalidade construída sobre relações sociais desiguais e repletas de preconceito impõe.

O que se percebe é que falta maturidade na prática cidadã e a cultura participativa e democrática é por demais incipiente nos espaços de gestão dos mosaicos. Não se trata apenas da questão de aprender a ouvir o outro e a dialogar francamente, mas principalmente da dificuldade em entender e aceitar os espaços coletivos como momentos de construção democrática para a melhoria do processo de gestão enquanto dimensão pública da política de conservação, e não como um lugar onde cada instituição age para se defender. Observou-se também ao longo do processo que é comum nas falas e posturas, primeiro a defesa institucional, sem que se entenda a natureza e a finalidade dos espaços de construção coletiva formados. É claro que nos espaços públicos, os interesses antagônicos se explicitam e os conflitos não serão resolvidos apenas pela boa vontade e pelo diálogo. A questão não é essa, e a idealização de um espaço público certamente não contribui para o amadurecimento democrático. O que está se colocando é a necessidade de, diante dos conflitos estruturais existentes, reconhecê-los e pactuar as finalidades possíveis de serem alcançadas em cada espaço estabelecido. Isso é radicalidade democrática e maturidade no convívio entre agentes sociais conflitantes.

Esse é um aspecto relevante e que deve ser destacado. Há, por vezes, relativa valorização dos espaços coletivos como conselhos, fóruns e comitês, mas sem uma discussão sobre os limites de atuação e uma predefinição do que é possível alcançar nestes. Recorrentemente há frustração e evasão dos participantes, quando as limitações existentes se tornam claras. Há situações "viciadas" em que a melhor alternativa pode ser deixar o espaço e denunciar as práticas irregulares, mas no geral, há possibilidades de avanços. Sem dúvida, condicionados por arranjos institucionais e interesses políticos e econômicos maiores.

Muitas vezes essas possibilidades são desperdiçadas, pois não se parte do reconhecimento do limite e dos avanços alcançáveis, mas de se querer tudo resolvido e encaminhado em situações nas quais isso é simplesmente inviável. A ação por projetos que se realizam no âmbito do Estado, sob as orientações Revbea, São Paulo, V.11, № 2: 342-356, 2016. 
de um determinado governo, mesmo que fortalecidas por conselhos legítimos e representativos, são indiscutivelmente limitadas pela conjuntura política.

Portanto, essa análise de conjuntura coletivamente empreendida no conselho do mosaico é uma condição primordial para que as estratégias sejam definidas e promovidas, seja pela via institucional formatada (eventos, GTs, conselhos, ação no ministério público, etc.), seja por vias de mobilização autônoma e popular (movimentos sociais, manifestações públicas, denúncias, fóruns populares, etc.), onde um movimento pode potencializar o outro. É desse modo que o controle social pode ser exercido "por dentro" e "por fora", ajudando a consolidar novos arranjos político-institucionais e instrumentos que permitam uma gestão participativa e integrada de territórios, objetivo maior da Educação Ambiental no âmbito da gestão de mosaicos de áreas protegidas.

\section{Referências}

ACSELRAD, H. O que é justiça ambiental. Rio de Janeiro: Garamond, 2009.

ACSELRAD, H. Conflitos ambientais no Brasil. Rio de Janeiro: Relume Dumará, 2004.

BROSE, M. (org.). Metodologia participativa: Uma introdução a 29 instrumentos. Porto Alegre: Tomo Editorial, 2001.

COSTA, F. A. M. (org.). Educomunicação socioambiental: comunicação popular e educação. Brasília: MMA, 2008.

FARIA, A.A.C. e NETO, P.S.F. Ferramentas do diálogo - qualificando o uso das técnicas do DRP: diagnóstico rural participativo. Brasília: MMA, 2006.

FLEURY, L., ALMEIDA, J. Populações tradicionais e conservação ambiental: uma contribuição da teoria social. Revista Brasileira de Agroecologia, Cruz Alta, ABA, v. 2, n. 3, 2007.

LOUREIRO, C.F.B. Sustentabilidade e educação: um olhar da ecologia

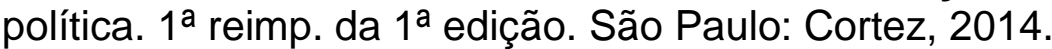

LOUREIRO, C.F.B.; AZAZIEL, M.; FRANCA, N. Educação Ambiental e conselho em unidades de conservação: aspectos teóricos e metodológicos. Rio de Janeiro: Ibase, 2007.

LOUREIRO, C.F.B.; AZAZIEL, M.; FRANCA, N. Educação Ambiental e gestão participativa em unidades de conservação. Rio de Janeiro: lbase/lbama, 2003.

LOUREIRO, C.F.B.; SAISSE, M. Educação Ambiental na gestão ambiental pública brasileira: uma análise da SEMA ao ICMBio. Revista educação pública, UFMT, v. 23, n. 52, jan./abril 2014.

LOUREIRO, C.F.B.; SAISSE, M.; CUNHA, C.C. Histórico da Educação Ambiental no âmbito federal da gestão ambiental pública: um panorama da divisão do Ibama à sua reconstrução no ICMBio. Desenvolvimento e Meio Ambiente, Curitiba, UFPr, v. 28, julho/dezembro de 2013. 
MELO, G. M. Desafios para a gestão integrada e participativa do Mosaico da Mata Atlântica Central Fluminense - RJ, Rio de Janeiro: UFRJ/CFCH Programa EICOS de Pós-Graduação, 2012.

MOUTINHO-DA-COSTA, L. Territorialidade e racismo ambiental: elementos para se pensar a Educação Ambiental crítica em unidades de conservação. Revista Pesquisa em Educação Ambiental, Rio Claro, UNESP, v. 6, n. 1, 2011.

PINHEIRO, M.R. (org.). Recomendações para reconhecimento e implementação de mosaicos de áreas protegidas. Brasília: GTZ, 2010.

QUINTAS, J. Como o IBAMA exerce a Educação Ambiental. Brasília: IBAMA, 2005.

QUINTAS, J.S. (org.) Pensando e praticando a Educação Ambiental na gestão do meio ambiente. Brasília: IBAMA, 2000.

YIN, R. Estudo de caso. 5a edição. Porto Alegre: Bookman companhia editorial, 2015. 